\title{
How to become a crab: Phenotypic constraints on a recurring body plan
}

Joanna M. Wolfe ${ }^{1 *}$, Javier Luque ${ }^{1,2,3}$, Heather D. Bracken-Grissom ${ }^{4}$

${ }^{1}$ Museum of Comparative Zoology and Department of Organismic \& Evolutionary Biology, Harvard University, 26 Oxford St, Cambridge, MA 02138, USA

${ }^{2}$ Smithsonian Tropical Research Institute, Balboa-Ancon, 0843-03092, Panama, Panama

${ }^{3}$ Department of Earth and Planetary Sciences, Yale University, New Haven, CT 06520-8109, USA

${ }^{4}$ Institute of Environment and Department of Biological Sciences, Florida International

University, Biscayne Bay Campus, 3000 NE 151 Street, North Miami, FL 33181, USA

*E-mail: jowolfe@g.harvard.edu

\section{Summary:}

A fundamental question in biology is whether phenotypes can be predicted by ecological or genomic rules. For over 140 years, convergent evolution of the crab-like body plan (with a wide and flattened shape, and a bent abdomen) at least five times in decapod crustaceans has been known as 'carcinization'. The repeated loss of this body plan has been identified as 'decarcinization'. We offer phylogenetic strategies to include poorly known groups, and direct evidence from fossils, that will resolve the pattern of crab evolution and the degree of phenotypic variation within crabs. Proposed ecological advantages of the crab body are summarized into a hypothesis of phenotypic integration suggesting correlated evolution of the carapace shape and abdomen. Our premise provides fertile ground for future studies of the genomic and developmental basis, and the predictability, of the crab-like body form.

Keywords: Crustacea, Anomura, Brachyura, Carcinization, Phylogeny, Convergent evolution, Morphological integration 


\section{Introduction}

Biologists strive to explain the evolution of form, and the drivers of biodiversity across related groups. Instances of convergent evolution are emerging model systems to link such evolutionary patterns and processes, as they provide naturally occurring experimental replicates, including evidence of shared phenotypic constraints. Here, we focus on the success of the crab body plan within the economically and ecologically significant decapod crustaceans, as a system to address these fundamental questions.

Crabs are one of the most iconic groups of invertebrates, as they play an integral role in the aquarium trade, fisheries and aquaculture, and are celebrated through festivals, parades, and social media memes, and as the constellation and astrological sign Cancer. The groups we refer to as crabs are members of two decapod crustacean infraorders, together known as Meiura. These comprise Brachyura or 'true' crabs (e.g. fiddler crabs, spider and decorator crabs, mud crabs, frog crabs, and swimming crabs), and Anomura or 'false' crabs (e.g. porcelain crabs, hermit and king crabs, mole crabs, and squat lobsters). The most visible difference between true and false crabs is the apparent difference in number of walking legs: four and three pairs, respectively (the posterior pair is present but reduced in anomurans, often concealed in the gill chamber). Several other features differentiate anomurans and brachyurans, such as the position of the molting plane of weakness, the length of the antennae (usually longer in anomurans), and the position of antennae with respect to the eyes (one pair to the side of the eyes in anomurans, both pairs of antennae between the eyes in brachyurans) (Scholtz and Richter 1995; Luque et al. 2019b). The overwhelming majority of extant decapod species $(>9,500$ of $\sim 15,000)$ are meiurans (De Grave et al. 2009). By contrast, the remaining diversity of decapods is distributed into nine other infraorders, including lobsters, crayfish, prawns, and shrimp.

Carcinization (a generally wide and flattened shape; Figure 1 and Box 1), or the crab-like body plan, has evolved at least five times, and has been lost several times within meiuran crustaceans (simplified in Figure 2). The reasons for repeated evolution of the crab-like body plan remain a mystery (Bracken-Grissom et al. 2013; Scholtz 2014), although there seems to be a correlation between body form and ecology (Luque et al. 2019b), such as protective and locomotory behaviors. Carcinized lineages thrive in almost every habitat on Earth, ranging from lively coral reefs to isolated marine caves, from abyssal oceanic plains to mountain streams, from terrestrial to aquatic ecosystems. Morphological disparity across carcinzed lineages is equally impressive, with body shapes in endless forms most beautiful, and sizes ranging from millimeters to meters. Given the high morphological variation, species richness, and broad distribution of extant crabs, and their rich fossil record (Figure 3), crabs are an ideal group to study trends in biodiversity through time. 


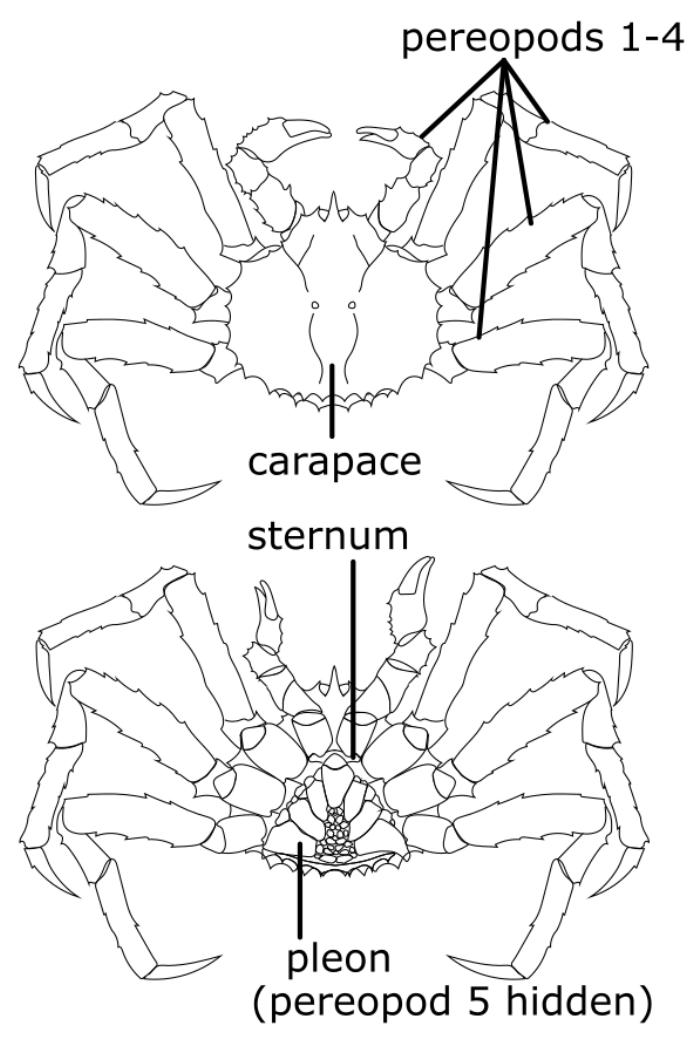

Figure 1. Basic anatomical terminology for an exemplar king crab (Lithodoidea: Lithodidae: Paralithodes camtschaticus).

Convergence is common on relatively recent timescales (fewer than 20 million years), such as in island ecomorphs in anoles (Losos 2011) and plants (Fernández-Mazuecos et al. 2020), mimicry in butterflies (Concha et al. 2019), and microbiota composition in carnivorous plants (Bittleston et al. 2018), among numerous examples. Ancient events (over 540 million years ago) also result in convergence, such as the evolution of metazoan eyes. In the latter cases, the phenotype is usually not replicated as precisely (Serb et al. 2017). Meiuran evolution reflects moderate distances between groups, approximately 200-350 million years (Wolfe et al. 2019). As we do not currently know whether parallelism (deep homology, or co-option of pre-existing ancestral mechanisms) or 'true' convergence (homoplasy, or similar phenotypes arising from completely different ancestors) underpins the crab-like body plan, we use the general term 'convergence' to refer to the pattern of repeated evolution of carcinization. The crab system is an emerging example where it is becoming possible to trace the pattern of convergence, infer shared constraints on the body form, and eventually uncover underlying mechanisms and new strategies to predict phenotypic evolution.

Box 1: Carcinization, or the crab-like body form, is perceived as a wide, flat oval or hexagonal shape, as opposed to the elongate, cylindrical shape of a lobster or mud shrimp. A major feature of carcinization is thus the flattening and bending of the pleon (abdomen), to fit beneath the carapace. Basic anatomy illustrated in Figure 1. Specific features common to most carcinized groups (Keiler et al. 2017) include: 
- A flattened and widened carapace (at least slightly wider than long), often with lateral margins (raised edges of the dorsal carapace)

- Sternites (sclerotized ventral segments) fused to some degree into a single wide plate called the thoracic sternum or plastron

- A flattened and bent 'abdomen' or pleon, hidden from dorsal view, partially or completely covering the thoracic sternum

- Loss or significant reduction of the uropods (appendages of the sixth pleonal somite, usually forming a tail fan in other decapods)

- Fusion of pleonal ganglia, reduction of pleonal muscles (documented for representative anomurans and two species of eubrachyuran: (Keiler et al. 2017; Castejón et al. 2018; Spitzner et al. 2018)

Decarcinization, or the secondary loss of the crab-like body form, has occurred multiple times in both Brachyura and Anomura. This form is more cylindrical, but has evolved from a wide oval shaped ancestor (Scholtz 2014; Luque et al. 2019b), as opposed to the ancestrally uncarcinized forms (that never evolved a crab-like form in the time since their common ancestor with mud shrimp). The striking similarity between uncarcinized and decarcinized groups has led to erroneous classification of certain decarcinized brachyurans as uncarcinized anomuran mole crabs (Boyko 2002); compare Figure 2C and 2K). Common features of decarcinized crabs include:

- An elongated, narrow carapace

- A pleon that is not strongly flattened and/or bent, and is sometimes visible in dorsal view or even elongated

- Legs with modified distal segments

There are varying degrees of carcinization and decarcinization (Scholtz 2014; Luque et al. 2019b), so not all species can be easily labeled as 'carcinized', 'uncarcinized', or 'decarcinized'. Some examples include: the coconut crab Birgus latro (a semi-carcinized anomuran with a bent pleon but incompletely fused sternites and no lateral margins) and other hermit crabs that have lost or reduced their domiciles; the porcelain crab Allopetrolisthes spinifrons (a 'hypercarcinized' anomuran with a sexually dimorphic pleon, strongly resembling brachyurans); the homolodromiid and homoloid brachyurans (which have characteristically carcinized pleons but lack wide carapaces and lateral margins; Figure 2B); the thumbnail crab Thia scutellata (a somewhat decarcinized eubrachyuran); and the gallforming cryptochirid crabs (decarcinized brachyurans, but with the female pleon modified as a large brood pouch) (Boyko 2002; Hiller et al. 2010; Anker and Paulay 2013; Vehof et al. 2016; Keiler et al. 2017).

\section{Carcinization has been gained and lost throughout decapod evolution}

Attempts to infer the convergent pattern of carcinized forms have inspired crustacean researcher for over 140 years (Boas 1880; Borradaile 1916; Cunningham et al. 1992; McLaughlin and Lemaitre 1997; McLaughlin et al. 2004; Tsang et al. 2011; Anker and Paulay 2013; Bracken-Grissom et al. 2013; Scholtz 2014; Keiler et al. 2017). From a hypothesis based on our previous phylogenetic contributions (Figure 2; (Bracken-Grissom et al. 2013; Luque et 
al. 2019b; Wolfe et al. 2019), evolution of carcinization has fully occurred once or twice in Brachyura ( $>7000$ species of true crabs), and at least three times during the evolution of Anomura (>2500 species) (Bracken-Grissom et al. 2013; Scholtz 2014; Keiler et al. 2017). Carcinization has been lost at least five times, and likely several other times, among fossil and living meiurans (Luque et al. 2019b), representing instances of decarcinization, or a dramatic departure from an ancestral crab-like body form. Note that the pattern of carcinization we primarily describe is not the only possible path of character evolution, but will provide a working hypothesis for the purposes of our discussion.

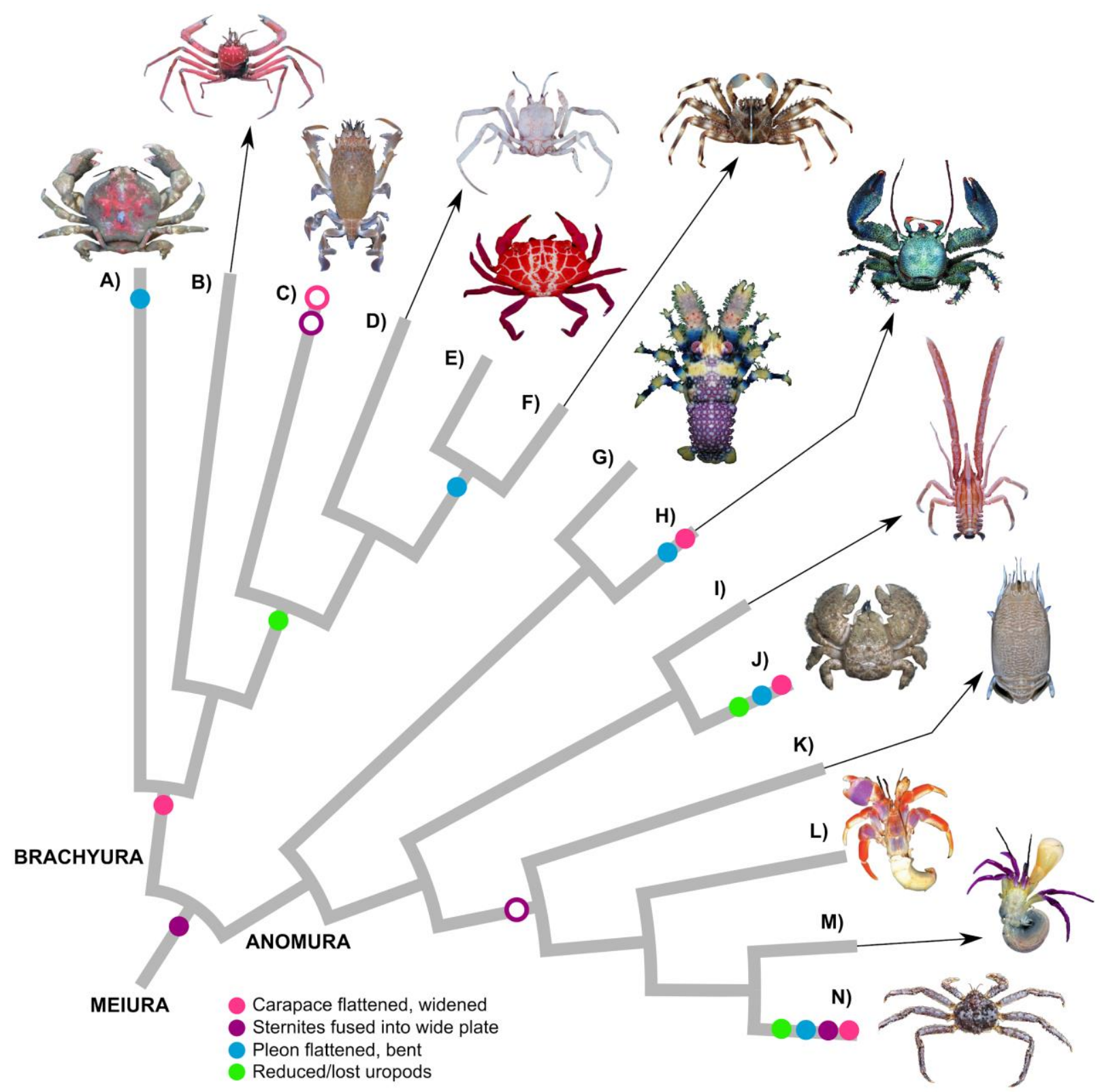

Figure 2. Gross morphology in the convergent evolution of representative true crabs (Brachyura), porcelain crabs (Porcellanidae), hairy stone crabs (Lomisidae), and king crabs (Lithodoidea). Losses (open circles) observed in frog crabs (Raninoidea). Topology simplified from (Bracken-Grissom et al. 2013; Luque et al. 2019b; Wolfe et al. 2019). Body plan features are assumed to be present in the 
common ancestor of each marked lineage but may vary considerably within each group, see Box $\mathbf{1}$ for further details. A) Dromioidea: Dromiidae: Conchoecetes intermedius (Phan Thiết, Vietnam). B) Homoloidea: Homolidae: Lamoha murotoensis (Taiwan). C) Raninoidea: Raninidae: Raninoides benedicti (Panama). D) Cyclodorippoidea: Cymonomidae: Cymonomus cognatus (Taiwan). E) Heterotremata: Xanthidae: Liomera rubra (Guam). F) Thoracotremata: Percnidae: Percnon planissimum (Taiwan). G) Galathoidea: Galatheidae: Galathea pilosa (Mo'orea, French Polynesia). H) Galatheoidea: Porcellanidae: Petrolisthes lamarckii (Taiwan). I) Chirostyloidea: Chirostylidae: Uroptychodes grandirostris (Taiwan). J) Lomisoidea: Lomisidae: Lomis hirta (South Australia). K) Hippoidea: Hippidae: Emerita portoricensis (Rio Grande do Norte, Brazil). L) Paguroidea: Coenobitidae: Coenobita clypeatus (Belize). M) Paguroidea: Paguridae: Pylopaguropsis lemaitrei (Mo'orea, French Polynesia). N) Lithodoidea: Lithodidae: Paralithodes camtschaticus (Narvik, Norway). Photo credits: A,N) Ondřej Radosta; B,D,H,I) Tin-Yam Chan; C,E,G,K,M) Arthur Anker; F) Ling-Kuang Tseng; J) Michael Marmach; L) Darryl Felder.

\subsection{Progress in resolving crab relationships}

Most prior phylogenetic studies have focused on the evolutionary pathway and ancestry of king crab carcinization (Figure 2L-N), addressing questions about the evolution 'from king [crab] to hermit [crab], or hermit to king'? (Cunningham et al. 1992; McLaughlin and Lemaitre 1997; Tsang et al. 2011; Bracken-Grissom et al. 2013; Noever and Glenner 2017). This focus stems from the importance of king crabs (Lithodidae) as a sought-after food source. Despite their carcinized appearance (with broad carapaces and reduced, bent abdomens), king crabs are anomurans; their affinity is immediately evident from the reduced posteriormost walking leg. Indeed, all recent phylogenetic work suggests king crabs have evolved from a paraphyletic grade of pagurid hermit crabs (Tsang et al. 2011; Bracken-Grissom et al. 2013; Noever and Glenner 2017; Wolfe et al. 2019). Other examples of carcinization, such as porcelain crabs and especially true crabs have often been excluded from detailed comparative research, though they offer similar insights into dramatic shifts in body morphology (Hiller et al. 2010; Keiler et al. 2015). Due to the narrow systematic focus of the past, the unparsimonious history of crab body plan evolution must be reconciled.

Numerous topologies have been proposed for the relationships among families within the infraorders Anomura and Brachyura. However, almost half of the branches on the crab tree of life remain dark, with the most comprehensive molecular studies including only $\sim 51 \%$ of the total extant families and $\sim 2 \%$ of the total species (Bracken-Grissom et al. 2013; Tsang et al. 2014). Previous studies have included a maximum of nine housekeeping genes, or whole mitogenomes, but are poorly resolved as these data are uninformative for deep branching events (Timm and Bracken-Grissom 2015; Tan et al. 2018a, 2018b). Although Sanger sequencing data exist for Anomura (Bracken-Grissom et al. 2013), fossils have not been included in the complimentary morphological matrix (and thus lack any robust systematic framework). Improved phylogenomic data could leverage recent sequencing of 410 exons (Wolfe et al. 2019) that represented only 32 species of meiurans. These loci obtained much stronger support at deep nodes than have previous mitogenomic analyses (Tan et al. 2018a, 2018b; Wolfe et al. 2019). Most anomuran nodes were strongly supported, but contradicted previous phylogenies (BrackenGrissom et al. 2013) on the position of mole crabs and relationships among non-paguroids. Several squat lobster and hermit crab lineages remain to be sampled. Deep brachyuran nodes were strongly supported (Wolfe et al. 2019), but the relationships between families had variable 
support depending on the models applied, and several key taxa were not included (such as most podotreme lineages, and freshwater crabs).

The podotreme brachyurans (Figure 2A-D, Figure 3E-I; with sexual openings borne on the coxa in females and males) are critical for inferring the polarity and ancestry of carcinization (and decarcinization). As of yet, molecular phylogenetics has been insufficient to resolve the puzzle of podotremes, therefore our depiction of their extant relationships in Figure 2 relies on morphological data. Anatomically, these crabs lie in between Anomura and Eubrachyura, though all current data strongly support a paraphyletic podotreme grade with brachyuran affinity (Luque et al. 2019a). Analysis of eight Sanger sequenced genes including 58 of $~ 100$ brachyuran families (Tsang et al. 2014), analyses of mitogenomes (Tan et al. 2018b, 2019), and a recent transcriptomic analysis (Ma et al. 2019) each recovered podotreme paraphyly (the former with weak support). Relationships recovered among podotremes were entirely contradictory between those analyses. Of 11 extant podotreme families, however, over one third lack molecular data: no sequences have been published for Poupiniidae, Lyreididae, and Phyllotymolinidae, and only a single 18S sequence is available for Homolodromiidae. Meanwhile, morphological trees, including fossils, have sampled more extensively from podotreme lineages (Luque et al. 2019a, 2019b). Thus, a major goal of future research should represent all meiuran families with morphological data, and all extant families with strongly supported phylogenomic data, for a well-resolved total evidence phylogeny.

\subsection{Novel body plans appear to have evolved in singleton species}

Throughout time, there are numerous meiurans where a single or a very few species have evolved either carcinization from uncarcinized ancestors, or decarcinization from carcinized ancestors. The most significant extant 'singleton' is the carcinized anomuran Lomis hirta (Figure 2J), forming the monotypic family Lomisidae endemic to the southern coast of Australia and Tasmania. Over 200 years ago, the species was classified as a member of the carcinized porcelain crabs. Further morphological examination suggested membership in the carcinized king crabs, however, L. hirta is now understood as a unique extant lineage (McLaughlin 1983). Morphological, Sanger, and mitogenomic data currently suggest this species is related to chirostyloid (Figure 2I) and aeglid squat lobsters (Schnabel et al. 2011; Bracken-Grissom et al. 2013; Tan et al. 2018b), all of which have uncarcinized forms.

The most significant fossil singleton is the decarcinized brachyuran Callichimaera perplexa (Luque et al. 2019b), a single species described from the Upper Cretaceous with a wide distribution in Colombia and the USA (Figure 3E, 5D). A possible related taxon is the fossil Retrorsichela laevis (Feldmann et al. 1993) from the Paleocene of New Zealand, which was originally described as a squat lobster. The shape of the fifth and sixth sternites are remarkably similar between $C$. perplexa and $R$. laevis. The claw morphology is also similar, though it is also seen in other un- and decarcinized taxa such as mole crabs (Figure $2 \mathbf{K}$ ) and frog crabs (Figure 2C), respectively (Luque et al. 2019b). Therefore, $R$. laevis, if it is indeed a brachyuran and closely related to $C$. perplexa, could be revised as a decarcinized form as well. 
The revelation of $C$. perplexa teases the potential of numerous extinct, but unpreserved, singletons. Return to an ancestral body plan appears to violate Dollo's Law, but such histories have been recorded in taxa that co-opted developmental or genetic mechanisms from a common ancestor (as in the simplified case of flower pigmentation; Esfeld et al. 2018). Conversely, new fossil discoveries could refine phylogenetic hypotheses (Mongiardino Koch and Parry 2020) and clades rather than singletons describing a more detailed sequence of evolutionary events, as in the stepwise decarcinization of frog crabs (Figure 3F-G; Luque et al. 2012).

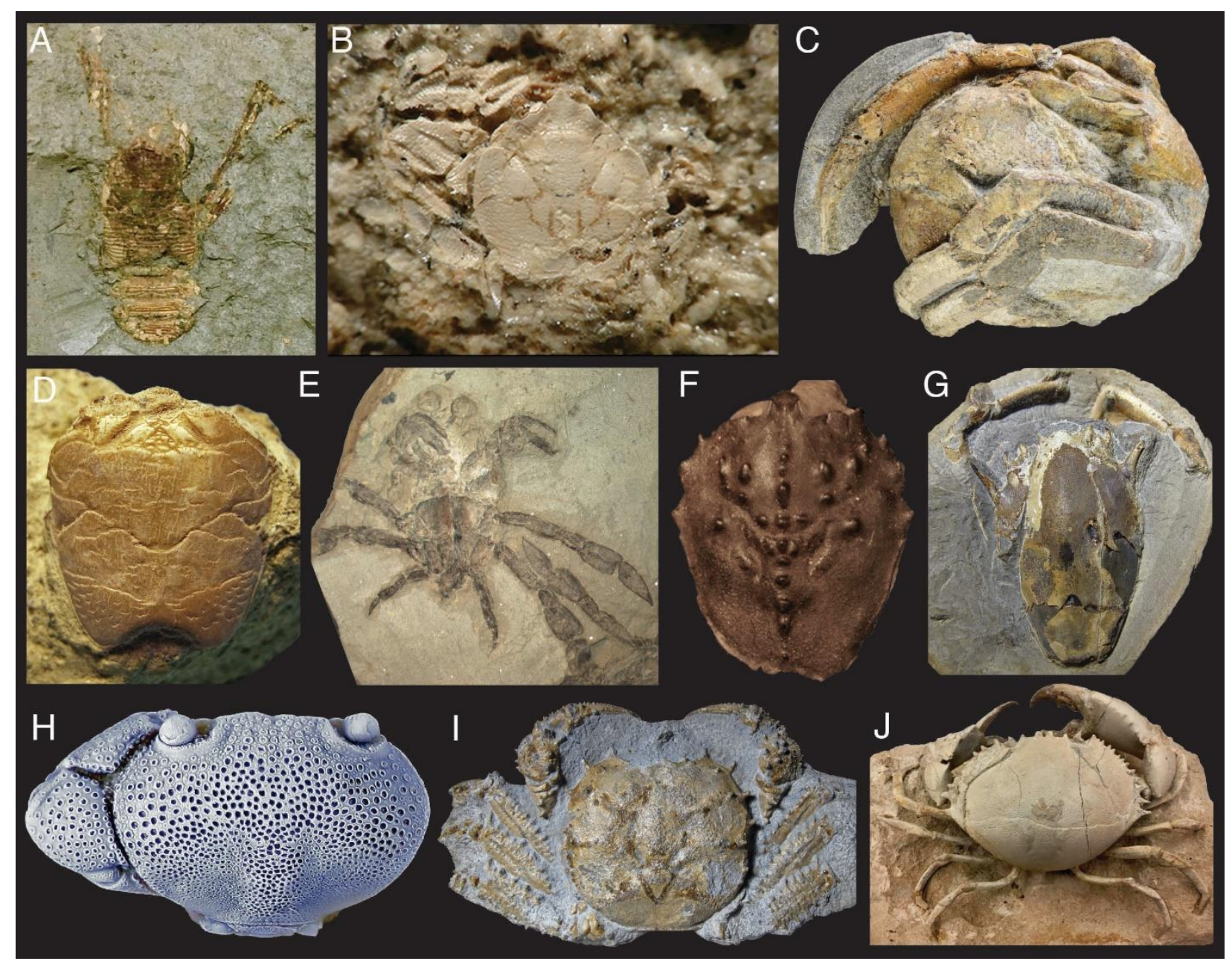

Figure 3. Comparison of fossil meiurans representing uncarcinized (A,C,D), carcinized (B,H-J), and decarcinized (E-G) body forms. A) Anomura: Galatheoidea: galetheoid indet. (Pliocene, Japan). B) Galatheoidea: Porcellanidae: Petrolisthes myakkensis (holotype UF 8678, late Pliocene, Florida, USA). C) Paguroidea: Diogenidae: Diogenes augustinus (holotype MPZ2020/54 articulated without its shell, left lateral view, mid Eocene, Spain). D) Hippoidea: Albuneidae: Italialbunea lutetiana (C-225-1, Eocene, Italy). E) Brachyura: Callichimaeroidea: Callichimaeridae: Callichimaera perplexa (paratype MUN-STRI 27044-02b, Late Cretaceous, Colombia). F) Palaeocorystoidea: Palaeocorystidae: Notopocorystes stokesi (USNM F736, Early Cretaceous, England). G) Raninoidea: Raninidae: Raninoides willapensis (C-064-1, Eocene, USA). H) Etyoidea: Feldmannidae: Caloxanthus americanus (NPL-62056, Late Cretaceous, USA). I) Dakoticancroidea: Dakoticancridae: Avitelmessus grapsoideus (187-3, Late Cretaceous, USA). J) Heterotremata: Carpilioidea: Zanthopsidae: Harpactocarcinus punctulatus (YPM 428818, Eocene, indet). Photo credits: A) Takashi Ito; B) from Luque et al. (2017), fig. 14A; C) Fernando Ari-Ferratges; D,G,I) Àlex Ossó; E,F,H,J) Javier Luque. 


\section{It is unclear whether the earliest crabs looked like crabs}

Morphologies of fossils close to the divergence time and position of a clade are instrumental to infer whether a trait is ancestrally shared or convergent within the group. Moreover, fossils allow phylogenies to be scaled by time for comparative analyses, and provide Earth history context for evolutionary events (Daniels et al. 2015; Schweitzer and Feldmann 2015; Davis et al. 2016). From fossil calibrated divergence time estimates, it does not appear that the breadth of crab body plan disparity was achieved early in the evolution of meiurans, due to an early molecular divergence $\sim 350$ million years ago, followed by a lag of $100+$ million years prior to the respective divergences of crown group anomurans and brachyurans (BrackenGrissom et al. 2013; Tsang et al. 2014; Wolfe et al. 2019). Brachyurans in particular have a rich and disparate Late Cretaceous and Cenozoic fossil record (Figure 3E-J), with bouts of morphological experimentation in several Late Cretaceous lineages. The fossil record prior to the Late Cretaceous is considerably more fragmentary (preserving mainly dorsal carapaces), obscuring understanding of early anatomical disparity and therefore the evolution of carcinized and decarcinized forms (Luque et al. 2019b).

The form of the common ancestor of meiurans and their sister group, the gebiid mud shrimp, may have resembled a mud shrimp itself (a burrower with an elongated carapace and abdomen). The ancestral form is inferred from a phylogenetic grade of mud shrimp (axiids and gebiids) relative to meiurans (Wolfe et al. 2019). Direct fossil evidence of mud shrimp prior to the Cretaceous is largely restricted to claw fragments and traces of their burrows (Hyžnỳ and Klompmaker 2015). Therefore, we suggest carcinized forms did not evolve prior to the stem group of meiurans. Unfortunately, the characteristics of the anomuran and brachyuran stem groups are still poorly understood, due to the lack of reliable fossils that can be assigned to either with certainty (Figure 4).

There are only three early fossil taxa with sufficiently complete preservation to inform ancestral states. The oldest putative brachyuran fossils are the Early Jurassic Eocarcinus praecursor (Feldmann and Schweitzer 2010) and Eoprosopon klugi (Figure 4B; Haug and Haug 2014). Both of these fossil taxa bear sub-cylindrical carapaces, reminiscent of those in modern homolodromiid crabs (related to the branches of Figure 2A and/or 2B; see Ahyong et al. 2007; Luque et al. 2019b). Crown group meiurans are united by a lack of chelate second and third pereopods (i.e. second and third thoracic legs do not have articulated claws: Scholtz and Richter 1995; Luque et al. 2019b; Hegna et al. 2020). In E. praecursor, the second and third pereopods are not fully visible, but have recently been reconstructed as distally simple based on multiple specimens (Scholtz 2020). These limbs cannot exclude a crown group meiuran affinity of the species, nor can they support anomuran affinity (Hegna et al. 2020; Scholtz 2020). Mounting evidence from the combination of total group brachyuran characters, and the lack of characters shared with crown group brachyuran taxa such as dromiaceans and homolids, together suggest that E. praecursor is a stem group brachyuran (Scholtz 2020). E. klugi exhibits similar character combinations, such as the carapace grooves, claws, and pleonal posture (Haug and Haug 2014), but it is challenging to discern details as there is only one specimen known. Together, these early fossils suggest the common ancestor of E. praecursor, E. klugi, and crown group brachyurans was not fully carcinized, possibly with a relatively wide carapace, a partially bent pleon, and may 
have lost uropods. It is possible that carcinization could have evolved multiple times, and to different degrees, within brachyurans (with Figure 2 as one hypothesis).
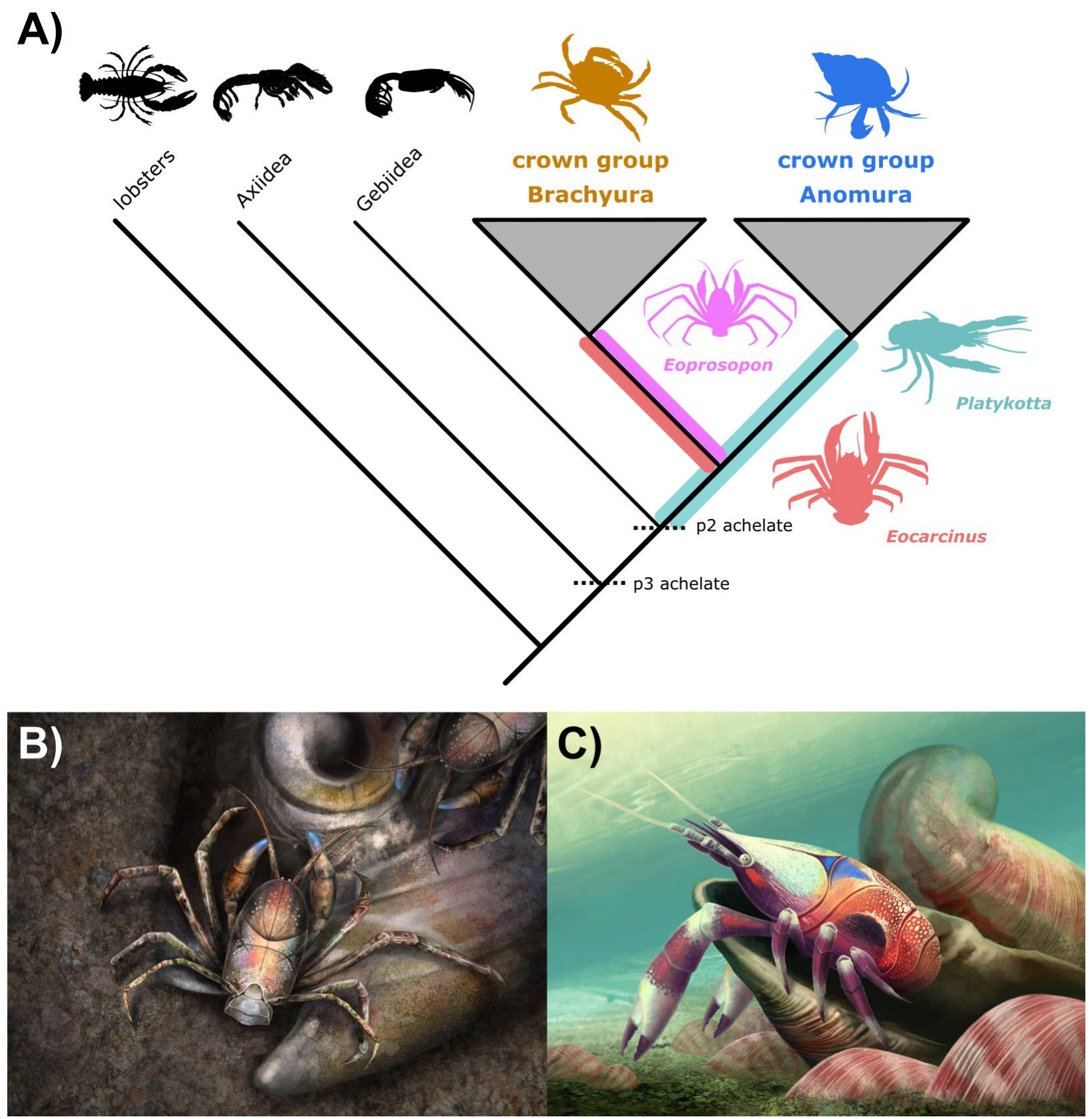

Figure 4. Diagnosing the affinities of early stem group crab fossils. A) Potential positions of early fossils following the favored phylogenomic hypothesis (Wolfe et al. 2019). Abbreviations $p 2, p 3$ refer to the second and third pereopods. Silhouettes from PhyloPic (phylopic.org), with fossils based on recent publications (Haug and Haug 2014; Hegna et al. 2020; Scholtz 2020). B) Artistic reconstruction of partly carcinized Eoprosopon klugi as a facultative scavenger. C) Artistic reconstruction of uncarcinized Platykotta akaina as a dweller of Triassic bivalve reefs. Reconstructions by Franz Anthony. 
The oldest putative anomuran is Platykotta akaina (Chablais et al. 2011) from the Late Triassic (Figure 4C). This lobster-looking and uncarcinized decapod shares features in common with some anomurans, and some that contradict a brachyuran affinity, but it is known from a single specimen and the evidence is not definitive (Hegna et al. 2020; Scholtz 2020). As with $E$. praecursor and E. klugi, the ventral morphology is poorly preserved. The original description reported chelate second pereopods (Chablais et al. 2011), which creates a contradiction. If $P$. akaina indeed has distal claws on the second pereopod, either a major character defining crown group Meiura (Scholtz and Richter 1995) is not parsimonious, or alternatively the species may fit well outside crown group Meiura (Hegna et al. 2020). Phylogenetic analyses (albeit with limited outgroup sampling) recovered $P$. akaina in either stem group anomuran or stem group meiuran positions (Luque et al. 2019b). Based on the information from each of the three important stem group taxa (Figure 4A), we hypothesize an uncarcinized ancestor for anomurans, though the ancestral state for crown group meiurans remains uncertain.

\section{The ecological advantages of becoming a crab are complex}

The ecological breadth of crabs (living in nearly every aquatic habitat on Earth) departs from the view where convergent phenotypes are under positive selection in their particular habitats (Losos 2011; Serb et al. 2017; Rincon-Sandoval et al. 2020). Scholtz (2014) noted that carcinization, if viewed as the overall evolution of a broad, rounded shape from a more elongated one, is known from other arthropods such as horseshoe crabs (whose common name leads to mistaken identity: these are chelicerates, not crustaceans). None of the non-meiuran groups known, however, share the bent pleon. It is likely that carcinization in meiurans provides ecological advantages relative to uncarcinized sister taxa (e.g. mud shrimps, squat lobsters), allowing them to occupy new and varied niches. These may be broadly characterized as adaptations for protection, locomotion, and feeding.

\subsection{The crab body plan may aid in protection and locomotion}

The feature of carcinization most frequently discussed as adaptive is the reduced, folded pleon. In uncarcinized decapods (including squat lobsters and hermit crabs), the elongated pleon is directly used for locomotion and predator avoidance, as in the behavioral caridoid escape reaction (i.e. tail-flip or backwards swimming; Faulkes 2008; Keiler et al. 2017). Bending of the abdomen in carcinization precludes the tail-flip behavior, but instead allows crabs to avoid predators by reducing the surface area exposed for attack. Calcification, the hardening of the pleonal cuticle usually observed in carcinization, further protects the animal from predators. The carcinized and calcified king crabs (Figure 1, Figure 2N) evolved from the shell-dwelling hermit crabs (Figure 2L-M). King crabs, and some partially carcinized hermit crabs including $B$. latro (Box 1; Reese 1968; Anker and Paulay 2013) have therefore abandoned their protective domiciles. The reasons are unclear, but may include moving into habitats where hiding under rocks may be favored over the additional expense of carrying the domicile (Blackstone 1989; Noever and Glenner 2017), or scenarios where gastropod shells of larger size were not available, forcing crabs to abandon their domiciles.

Carcinization may confer other advantages, such as improvements to locomotion. The bent pleon in combination with the flattened carapace allows a lower center of gravity than in 
uncarcinized decapods, freeing the posterior appendages for improved function (Scholtz 2020), particularly the sideways walking that typifies crabs. The sideways stance provides equally fast speeds when walking in either direction (Vidal-Gadea et al. 2008), improving predator avoidance from merely hiding to an agile, active behavior. However, sideways walking is not observed in all carcinized lineages (e.g. forward-walking spider crabs and anomuran king crabs), and some uncarcinzed hermit crabs can walk sideways (Vidal-Gadea et al. 2008; Chapple 2012; Anker and Paulay 2013). Improvements to mobility may also be characterized by reduced uropods associated with carcinization (Figure 2; Hiller et al. 2010), and specialized structures related to reproduction and pleonal positioning (Guinot and Bouchard 1998; Guinot et al. 2013; Köhnk et al. 2017a, 2017b). Therefore, it appears that a general posture of the pleon is the main requirement for locomotory benefits of carcinization, which can be achieved through various morphological pathways.

Decarcinization has occurred several times, despite the presumed loss of advantages from the exposed abdomen and loss of sideways walking ability. Most decarcinized groups consist of singletons (Section 2.2) or groups with few extant species, such as the eubrachyuran family Corystidae and the porcelain crab genera Euceramus and Porcellanella. If all decarcinized groups were singletons or had very limited diversity, it could be hypothesized that decarcinization represents an evolutionary dead-end. Contradictory evidence comes from Raninoidea, or frog crabs (Figure 2C, Figure 3F-G), a clade with low extant diversity (48 species) but also with >200 fossil decarcinized members dating back to the Early Cretaceous (Luque et al. 2012; Luque 2015). Therefore, the crab-like body plan cannot represent an optimum for all niches, and may be subject to functional trade-offs that allow the evolution (and sometimes persistence) of decarcinization. Extant frog crabs inhabit sediments with few hiding places, and have adopted a fossorial lifestyle where rapid burying may protect the animal from predation (Luque et al. 2012; Fraaije et al. 2018), but also concealing the animal as an ambush predator itself (Luque et al. 2019b). Perhaps the fossorial lifestyle exchanges lateral mobility for different protective benefits or larger body size (Klompmaker et al. 2015), a trade-off that may allow frog crabs to persist and diversify (Cyriac and Kodandaramaiah 2018). Future studies of functional morphology should explicitly compare carcinized and non-carcinized taxa and their behaviors to better delineate benefits of the crab-like form.

\subsection{Escalation of predation cannot explain early crab success}

A feature of carcinization, observed mainly in eubrachyurans (Figure 2E-F) and some carcinized anomurans, is the development of laterally mobile claws (Anker and Paulay 2013), which, when mineralized and adapted into forms that suit ecology, have been associated with the ability to crush prey and potentially diversification of the predatory crab groups. The evolution of crabs and their efficiency as shell-crushing predators, by adaptation of their claw morphology, has been implicated as a driver of an ecological arms race called the Mesozoic Marine Revolution. During this time, fauna such as molluscs and echinoderms evolved stronger and more heavily ornamented morphologies, possibly as a response to predation by decapod crustaceans (Vermeij 1977; Knoll and Follows 2016). Studies of prey taxa have focused on gastropods (Palmer 1979; Seeley 1986) and their fossils as a proxy recording defensive evolutionary trends towards the end of the Mesozoic (Vermeij 1977; Cunha 2019). Fossil crab claws that appear specialized for crushing hard-shelled prey (e.g. with asymmetrical claws, 
'molariform' protrusions on the claw tips, and/or curved 'teeth' on the proximal claw that aid in peeling open shells; Schweitzer and Feldmann 2010) are first recorded from 'mid' to Late Cretaceous deposits (Dietl and Vega 2008; Luque et al. 2017, 2020; Prado et al. 2018; Robin et al. 2019), concurrent with the divergence (Wolfe et al. 2019) of eubrachyuran groups with known heavy shell predators such as xanthoids and portunoids during the so-called 'Cretaceous Crab Revolution' (Luque et al. 2019b).

Upon closer examination, however, the hypothesis of claw morphology and predation ability on hard-shelled invertebrates as a major influence on the evolutionary success of crabs and their carcinized body plans is overstated. Large claws can have other functions, including sexually selected weapons in fiddler crabs, which do not confer prey crushing ability but are crucial for signaling and antagonistic behaviors (Swanson et al. 2013; Fujiwara and Kawai 2016). Therefore, many taxa bearing large, ornamented, and mineralized claws are not predators. The functional relationship between carcinized forms and shell-crushing is diluted by the presence of mineralized, asymmetrical, and ornamented claws and crushing mandibles in other decapods, such as lobsters (Schweitzer and Feldmann 2010; Scholtz 2014), and by varied crab diets including herbivory (Schweitzer and Feldmann 2010; Boudreau and Worm 2012; Poore et al. 2017; Wang et al. 2020). Of the carcinized anomurans, only porcelain crabs (Figure 2H) have a known Mesozoic fossil record (Robins and Klompmaker 2019; Wolfe et al. 2019). Although porcelain crabs and L. hirta (Figure 2J) have broad claws, these taxa are mainly filter feeders, occasionally using their claws to scrape algae (Kropp 1981). While some king crabs (Figure 1, Figure 2N) are indeed reported as shell-crushing predators with heavily calcified claws (Steffel et al. 2019), they appeared $\sim 35$ million years after the end of the Mesozoic (Bracken-Grissom et al. 2013).

Overall, there is little relationship observed between gross claw morphology and function, and the timing or success of carcinization. While predation represents an effective ecological strategy for many groups of meiurans (and investigations into species of aquacultural interest may corroborate predatory behaviors, e.g. Daly et al. 2020), it cannot be directly related to the evolution of body form or success of those clades.

\section{The crab body plan as a case of phenotypic integration}

Repeated evolution of the crab body plan may entail phenotypic integration, or covariation among body parts (Olson and Miller 1958; Figure 5). Integration, usually attributed to functional or developmental relationships between the body parts, shapes phenotypic evolution in various animal systems, such as correlation between regions of vertebrate skulls (e.g. Evans et al. 2017; Watanabe et al. 2019; Fabre et al. 2020), heads and mandibles in ants (Barden et al. 2020), and appendage segments in mantis shrimp (Anderson et al. 2016). Above, we described possible ecological benefits for pleonal reduction in crabs, improving their ability to hide in narrow spaces and move faster. We hypothesize that carcinization broadly represents an example of morphological and functional integration, wherein the bent pleon has coevolved with the flattened and widened carapace. 
A)

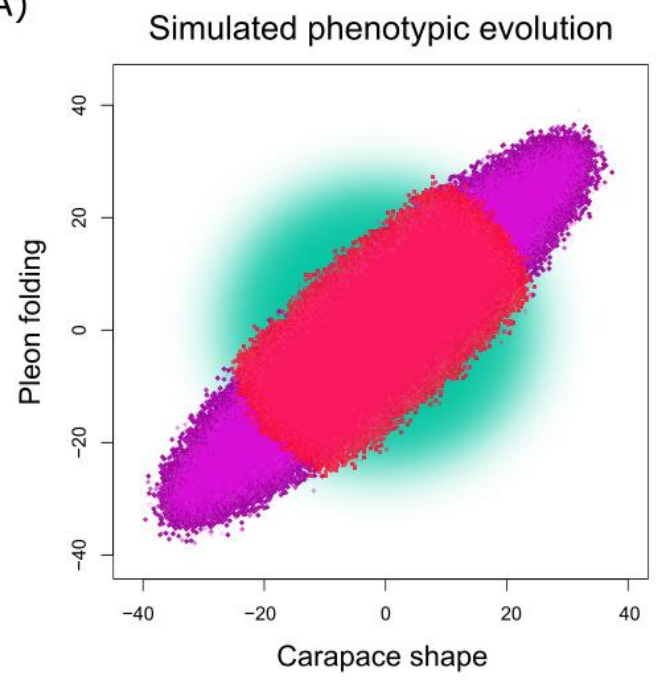

B)

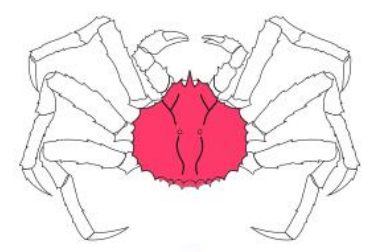

C)
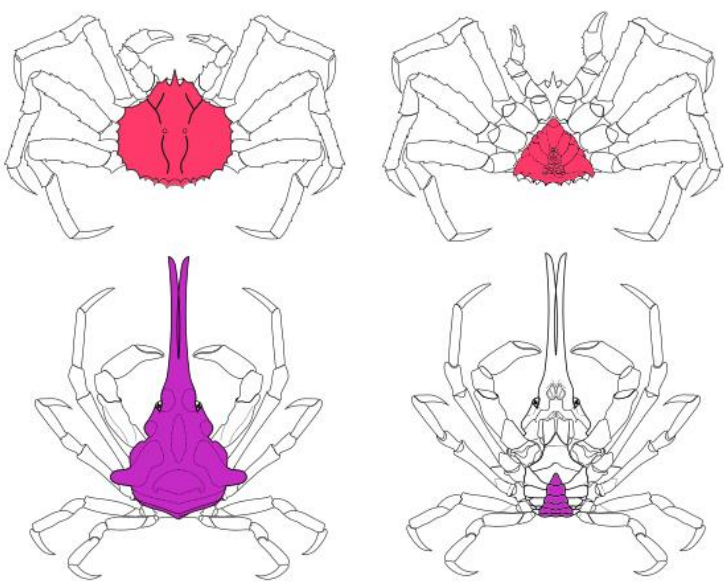

D)
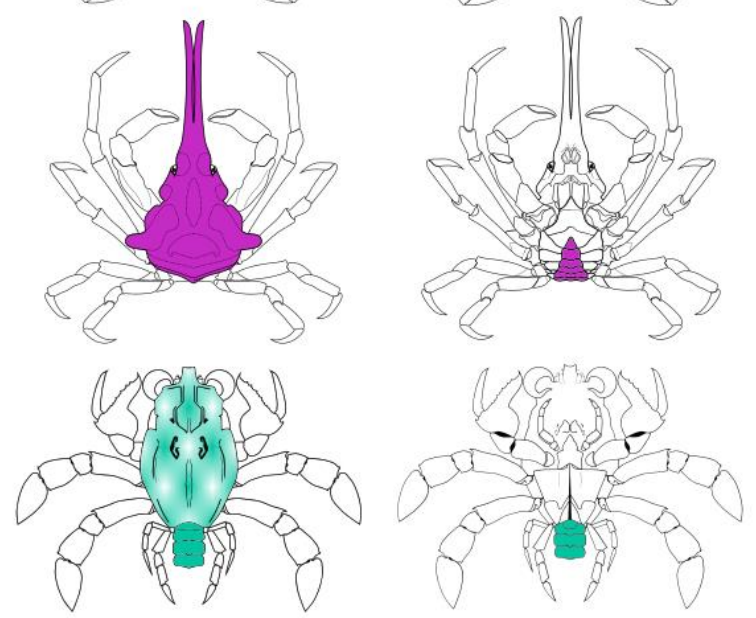

Figure 5. The crab-like body plan is an example of phenotypic integration. A) Approximate areas of morphospace explored by simulations of phenotypic evolution, after (Goswami et al. 2014; Felice et al. 2018). Integrated structures (pink and violet) are constrained in the direction of variance, but over time will achieve greater disparity in those directions (violet) relative to traits that are decoupled (cyan). B) Example of integration between the dorsal carapace and pleon in a carcinized taxon (Lithodoidea:

Lithodidae: Paralithodes camtschaticus). C) Example of integration facilitating evolution of an extreme phenotype in a carcinized taxon (Majoidea: Epialtidae: Oxypleurodon alisae). D) Example of decoupled evolution of the carapace (cyan gradient) and pleon (solid cyan) in a decarcinized taxon

(Callichimaeroidea: Callichimaeridae: Callichimaera perplexa).

Certain carcinized features may predispose the emergence of others, such as the bent pleon necessitating reduction of pleonal muscles and fused pleonal ganglia (Keiler et al. 2017). In brachyurans, pleon holding structures correlate with the evolution of carcinization (Guinot and Bouchard 1998; Köhnk et al. 2017b, 2017a), while king crabs calcified and folded the soft asymmetrical abdomen of an ancestral hermit crab form (Keiler et al. 2017). In most carcinized meiurans, the characteristic pleonal folding occurs fairly late in development, at the transition from planktonic megalopa stage to benthic juvenile forms (McLaughlin et al. 2004, Martin et al. 2014; Spitzner et al. 2018). Freshwater taxa exhibit extended brood care, which lack the metamorphic transition and hatch immediately as relatively carcinized juveniles (Guinot 2011; Vogt 2013). For decarcinized taxa with known development, the pleon is reduced but never folded (e.g. Minagawa 1990). Perhaps decarcinized or partially carcinized taxa exhibit pedomorphosis (Luque et al. 2019b), wherein the carapace and pleon never become integrated in adults (Figure 5D).

While the relationship between carcinization and pleonal bending appears straightforward, the carapaces of meiurans exhibit substantial morphological disparity. Figures 1-3 depict relatively classical examples of dorsal morphology for carcinized, uncarcinized, and decarcinized taxa, but there are many exceptions within phenotypic categories (Box 1) as well as 'extreme' morphologies, such as the teardrop shaped arrow crabs (the brachyuran Stenorhynchus 
and the squat lobster Chirostylus) with legs more than twice the body length, or elbow crabs (Parthenopidae) with triangular carapaces and elongated claws. A preliminary study of shape evolution has been conducted on meiuran dorsal carapaces, for five brachyurans and one king crab (Scholtz et al. 2020), finding greater shape similarity between four of the brachyurans and the king crab and little between the majoid (spider or decorator crab; an example in Figure 5C) and other brachyurans. If extremes such as the spider crabs can override relationships from both phylogeny and convergence, integration of the crab body plan seems to contradict previous wisdom that described a tension between integration as a set of constraints that limit phenotypic evolution, and the alternative of separate phenotypic modules that can diverge rapidly and therefore generate disparity (Goswami et al. 2014, 2015; Felice et al. 2018). However, a growing number of recent studies have uncovered strong integration of body structures alongside and even facilitating high disparity (e.g. Watanabe et al. 2019; Hedrick et al. 2020; Michaud et al. 2020). In some clades, integrated body parts may explore fewer overall directions of morphospace than independent structures, but they can attain a great range of shapes within those phenotypic constraints (Goswami et al. 2015; Felice et al. 2018; Figure 5A-C). For crabs, it has been proposed that divergent carapace shapes may help taxa invade new communities where local areas of morphospace are already occupied (Farré et al. 2020). Overall, phenotypic integration is a sensible macroevolutionary expression of convergent evolution (Goswami et al. 2014; Sherratt et al. 2017), and its pattern should be compared with convergence in carcinization.

\section{Towards predicting the evolution of crabs}

From a mechanistic perspective, phenotype is the expressed result of genomic and transcriptomic regulation of development. Therefore, the constraints leading to convergent evolution of carcinization may share an underlying genomic signature. Such a proposal may seem counterintuitive given the morphological and functional differences between carcinized clades; however, deep homology of development often typifies the evolution of integrated structures (Goswami et al. 2014).

It is only within the last year that high-quality genomic resources have become available for meiurans, though only for carcinized members. One species of eubrachyuran, Portunus trituberculatus (Lv et al. 2020; Tang et al. 2020c) and one species of king crab, Paralithodes platypus (Tang et al. 2020a) now have published chromosome-level genome assemblies. The eubrachyuran Eriocheir japonica sinensis has a recently updated genome assembly (Song et al. 2016; Tang et al. 2020b). To enable comparative research on whether genomic changes have a relationship to the phenotypic changes defining carcinization, it will be essential to assemble further genome sequences, particularly for decarcinized and uncarcinized meiurans.

Currently, little is known about development of crustacean carapaces, or pleonal growth. Outgrowth of the dorsal carapace has been studied in the water flea Daphnia magna and in the amphipod Parhyale hawaiensis (Shiga et al. 2017), both of which are hundreds of millions of years diverged from decapods. Nonetheless, candidate genes from the gene regulatory network patterning the fly wing were expressed in the margin of the D. magna carapace (Shiga et al. 2017), suggesting that the dorsal carapace may share deep homology with proximal leg segments in other crustaceans, in addition to the insect wing (Bruce and Patel 2020). Meanwhile, there are few obvious candidate genes for bending of the pleon in meiurans. Loci of interest could be 
identified by comparing transcriptomes across the metamorphosis from megalopa larva to juvenile, when the pleon becomes folded in most crabs. One study (Lv et al. 2020) has implicated decreased expression in the $P$. trituberculatus transcriptome at exactly this stage for the Hox genes $U b x$ and $a b d-A$ (expression of the latter patterns the pleon in P. hawaiensis: Martin et al. 2016; Serano et al. 2016). More is known about the genomics of metamorphosis in lobsters (Ventura et al. 2018) and shrimp (Zhang et al. 2019) than in meiurans. Therefore, it will be necessary to explore 'novel' or taxon-restricted and non-coding loci that share more sequence or expression similarity based on degree of carcinization than on the species relationships. As phylogenetic relationships among meiruans move towards resolution (Section 2), comparative methods could be used to identify genomic targets (e.g. Smith et al. 2020; Yusuf et al. 2020). Of course, convergent evolution may be predictable at some hierarchical levels of biological organization, but not at others (e.g. Concha et al. 2019; Lamichhaney et al. 2019). Nevertheless, assembly of genomic resources and multiple bioinformatic approaches may reveal genomic evidence for the possibility to predict that a crustacean would undergo carcinization.

\section{Conclusions}

Convergent gains and losses of the crab-like body plan provide an excellent system to examine the predictability of phenotypic evolution and body form over macroevolutionary timescales. Understanding the ecological and genomic basis underlying convergence in body form will contribute to the importance of constraints across the tree of life (e.g. Losos 2011; Agrawal 2017). Key priorities for future investigations should include: (1) phylogenomic sampling of poorly studied groups to better resolve the pattern of evolution of carcinization, (2) functional morphological research comparing anomurans and brachyurans to uncover the selective benefits of carcinization, (3) morphological comparisons interrogating the pattern of phenotypic integration and modularity in crabs, and (4) the assembly of genomes for exemplar carcinized and decarcinized taxa for comparative studies. Together, phylogenetic, morphological, and genomic evidence will reveal a comprehensive evolutionary scenario describing how to become a crab.

Acknowledgements: We thank our colleagues who shared photos, and Franz Anthony for collaboration on fossil reconstructions. This work was supported by the National Science Foundation DEB \#1856679 to J.M.W., DEB \#1856667 to H.D.B.-G., and a National Science and Engineering Research Council of Canada (NSERC) Postdoctoral Fellowship to J.L. 


\section{References:}

Agrawal A.A. 2017. Toward a Predictive Framework for Convergent Evolution: Integrating Natural History, Genetic Mechanisms, and Consequences for the Diversity of Life. Am. Nat. 190:S1-S12.

Ahyong S.T., Lai J.C.Y., Sharkey D., Colgan D.J., Ng P.K.L. 2007. Phylogenetics of the brachyuran crabs (Crustacea: Decapoda): The status of Podotremata based on small subunit nuclear ribosomal RNA. Mol. Phylogenet. Evol. 45:576-586.

Anderson P.S.L., Smith D.C., Patek S.N. 2016. Competing influences on morphological modularity in biomechanical systems: a case study in mantis shrimp. Evol. Dev. 18:171-181.

Anker A., Paulay G. 2013. A remarkable new crab-like hermit crab (Decapoda: Paguridae) from French Polynesia, with comments on carcinization in the Anomura. Zootaxa. 3722:293.

Barden P., Perrichot V., Wang B. 2020. Specialized Predation Drives Aberrant Morphological Integration and Diversity in the Earliest Ants. Curr. Biol. 30:3818-3824.e4.

Bittleston L.S., Wolock C.J., Yahya B.E., Chan X.Y., Chan K.G., Pierce N.E., Pringle A. 2018. Convergence between the microcosms of Southeast Asian and North American pitcher plants. eLife. 7:e36741.

Blackstone N.W. 1989. Size, shell-living and carcinization in geographic populations of a hermit crab, Pagurus hirsutiusculus. J. Zool. 217:477-490.

Boas J.E.V. 1880. Studier over decapodernes Slaegtskabsforhold. K. Dan. Vidensk. Skr. 6:3.

Borradaile L.A. 1916. Crustacea. Part II. - Porcellanopagurus: An instance of Carcinization. Brit Ant Terra Nova Exped 1910 Nat Hist Rep Zool. 3:111-126.

Boudreau S., Worm B. 2012. Ecological role of large benthic decapods in marine ecosystems: a review. Mar. Ecol. Prog. Ser. 469:195-213.

Boyko C.B. 2002. A Worldwide Revision of the Recent and Fossil Sand Crabs of the Albuneidae Stimpson and Blepharipodidae, New Family (Crustacea: Decapoda: Anomura: Hippoidea). Bull. Am. Mus. Nat. Hist. 272:1-396.

Bracken-Grissom H.D., Cannon M.E., Cabezas P., Feldmann R.M., Schweitzer C.E., Ahyong S.T., Felder D.L., Lemaitre R., Crandall K.A. 2013. A comprehensive and integrative reconstruction of evolutionary history for Anomura (Crustacea: Decapoda). BMC Evol. Biol. 13:128.

Bruce H.S., Patel N.H. 2020. Knockout of crustacean leg patterning genes suggests that insect wings and body walls evolved from ancient leg segments. Nat. Ecol. Evol. 4:1703-1712.

Castejón D., Alba-Tercedor J., Rotllant G., Ribes E., Durfort M., Guerao G. 2018. Micro-computed tomography and histology to explore internal morphology in decapod larvae. Sci. Rep. 8:1-11.

Chablais J., Feldmann R.M., Schweitzer C.E. 2011. A new Triassic decapod, Platykotta akaina, from the Arabian shelf of the northern United Arab Emirates: earliest occurrence of the Anomura.

Paläontol. Z. 85:93-102.

Chapple W. 2012. Kinematics of walking in the hermit crab, Pagurus pollicarus. Arthropod Struct. Dev. 41:119-131.

Concha C., Wallbank R.W.R., Hanly J.J., Fenner J., Livraghi L., Rivera E.S., Paulo D.F., Arias C., Vargas M., Sanjeev M., Morrison C., Tian D., Aguirre P., Ferrara S., Foley J., Pardo-Diaz C., Salazar C., Linares M., Massardo D., Counterman B.A., Scott M.J., Jiggins C.D., Papa R., Martin A., McMillan W.O. 2019. Interplay between Developmental Flexibility and Determinism in the Evolution of Mimetic Heliconius Wing Patterns. Curr. Biol. 29:S0960982219313168.

Cunha T. 2019. Gastropod phylogeny, biogeography and shell shape evolution. PhD thesis, Harvard University, Cambridge, MA, USA.

Cunningham C.W., Blackstone N.W., Buss L.W. 1992. Evolution of king crabs from hermit crab ancestors. Nature. 355:539-542.

Cyriac V.P., Kodandaramaiah U. 2018. Digging their own macroevolutionary grave: fossoriality as an evolutionary dead end in snakes. J. Evol. Biol. 31:587-598.

Daly B.J., Eckert G.L., Long W.C. 2020. Moulding the ideal crab: implications of phenotypic plasticity for crustacean stock enhancement. ICES J. Mar. Sci. fsaa043. 
Daniels S.R., Phiri E.E., Klaus S., Albrecht C., Cumberlidge N. 2015. Multilocus Phylogeny of the Afrotropical Freshwater Crab Fauna Reveals Historical Drainage Connectivity and Transoceanic Dispersal Since the Eocene. Syst. Biol. 64:549-567.

Davis K.E., Hill J., Astrop T.I., Wills M.A. 2016. Global cooling as a driver of diversification in a major marine clade. Nat. Commun. 7:13003.

De Grave S., Pentcheff D., Ahyong S.T., Chan T.-Y., Crandall K.A., Dworschak P.C., Felder D.L., Feldmann R.M., Fransen C.H.J.M., Goulding L.Y.D., Lemaitre R., Low M.E.Y., Martin J.W., Ng P.K.L., Schweitzer C.E., Tan S.H., Tshudy D., Wetzer R. 2009. A classification of living and fossil genera of decapod crustaceans. Raffles Bull. Zool. 21:1-109.

Dietl G.P., Vega F.J. 2008. Specialized shell-breaking crab claws in Cretaceous seas. Biol. Lett. 4:290293.

Esfeld K., Berardi A.E., Moser M., Bossolini E., Freitas L., Kuhlemeier C. 2018. Pseudogenization and Resurrection of a Speciation Gene. Curr. Biol. 28:3776-3786.e7.

Evans K.M., Waltz B.T., Tagliacollo V.A., Sidlauskas B.L., Albert J.S. 2017. Fluctuations in Evolutionary Integration Allow for Big Brains and Disparate Faces. Sci. Rep. 7:40431.

Fabre A.-C., Bardua C., Bon M., Clavel J., Felice R.N., Streicher J.W., Bonnel J., Stanley E.L., Blackburn D.C., Goswami A. 2020. Metamorphosis shapes cranial diversity and rate of evolution in salamanders. Nat. Ecol. Evol. 8:1129-1140.

Farré M., Lombarte A., Tuset V.M., Abelló P. 2020. Shape matters: relevance of carapace for brachyuran crab invaders. Biol. Invasions.

Faulkes Z. 2008. Turning Loss Into Opportunity: The Key Deletion of an Escape Circuit in Decapod Crustaceans. Brain. Behav. Evol. 72:251-261.

Feldmann R.M., Schweitzer C.E. 2010. Is Eocarcinus Withers, 1932, a Basal Brachyuran? J. Crustac. Biol. 30:241-250.

Feldmann R.M., Tshudy D.M., Thomson M.R. 1993. Late Cretaceous and Paleocene decapod crustaceans from James Ross Basin, Antarctic Peninsula. Mem. Paleontol. Soc. 28:1-41.

Felice R.N., Randau M., Goswami A. 2018. A fly in a tube: Macroevolutionary expectations for integrated phenotypes. Evolution. 72:2580-2594.

Fernández-Mazuecos M., Vargas P., McCauley R.A., Monjas D., Otero A., Chaves J.A., Guevara Andino J.E., Rivas-Torres G. 2020. The Radiation of Darwin's Giant Daisies in the Galápagos Islands. Curr. Biol. 30:S0960982220313506.

Fujiwara S., Kawai H. 2016. Crabs grab strongly depending on mechanical advantages of pinching and disarticulation of chela. J. Morphol. 277:1259-1272.

Goswami A., Smaers J.B., Soligo C., Polly P.D. 2014. The macroevolutionary consequences of phenotypic integration: from development to deep time. Philos. Trans. R. Soc. B Biol. Sci. 369:20130254.

Goswami A., Binder W.J., Meachen J., O'Keefe F.R. 2015. The fossil record of phenotypic integration and modularity: A deep-time perspective on developmental and evolutionary dynamics. Proc. Natl. Acad. Sci. 112:4891-4896.

Guinot D. 2011. The position of the Hymenosomatidae MacLeay, 1838, within the Brachyura (Crustacea, Decapoda). Zootaxa. 2890:40-52.

Guinot D., Bouchard J.-M. 1998. Evolution of the abdominal holding systems of brachyuran crabs (Crustacea, Decapoda, Brachyura). Zoosystema. 20:613-694.

Guinot D., Tavares M., Castro P. 2013. Significance of the sexual openings and supplementary structures on the phylogeny of brachyuran crabs (Crustacea, Decapoda, Brachyura), with new nomina for higher-ranked podotreme taxa. Zootaxa. 3665:7-414.

Haug C., Haug J.T. 2014. Eoprosopon klugi (Brachyura)-the oldest unequivocal and most "primitive" crab reconsidered. Palaeodiversity. 7:149-158.

Hedrick B.P., Mutumi G.L., Munteanu V.D., Sadier A., Davies K.T.J., Rossiter S.J., Sears K.E., Dávalos L.M., Dumont E. 2020. Morphological Diversification under High Integration in a Hyper Diverse Mammal Clade. J. Mamm. Evol. 27:563-575. 
Hegna T.A., Luque J., Wolfe J.M. 2020. The fossil record of the Pancrustacea. In: Poore G.C.B., Thiel M., editors. Evolution and Biogeography. Oxford: Oxford University Press. p. 21-52.

Hiller A., Viviani C.A., Werding B. 2010. Hypercarcinisation: an evolutionary novelty in the commensal porcellanid Allopetrolisthes spinifrons (Crustacea: Decapoda: Porcellanidae). Nauplius. 18:95102.

Hyžnỳ M., Klompmaker A.A. 2015. Systematics, phylogeny, and taphonomy of ghost shrimps (Decapoda): a perspective from the fossil record. Arthropod Syst. Phylogeny. 73:401.

Keiler J., Richter S., Wirkner C.S. 2015. Evolutionary morphology of the organ systems in squat lobsters and porcelain crabs (Crustacea: Decapoda: Anomala): An insight into carcinization. J. Morphol. 276:1-21.

Keiler J., Wirkner C.S., Richter S. 2017. One hundred years of carcinization-the evolution of the crablike habitus in Anomura (Arthropoda: Crustacea). Biol. J. Linn. Soc. 121:200-222.

Klompmaker A.A., Schweitzer C.E., Feldmann R.M., Kowalewski M. 2015. Environmental and scaledependent evolutionary trends in the body size of crustaceans. Proc. R. Soc. B Biol. Sci. 282:20150440.

Knoll A.H., Follows M.J. 2016. A bottom-up perspective on ecosystem change in Mesozoic oceans. Proc. R. Soc. B Biol. Sci. 283:20161755.

Köhnk S., Gorb S., Brandis D. 2017a. The morphological and functional variability of pleon-holding mechanisms in selected Eubrachyura (Crustacea: Decapoda). J. Nat. Hist. 51:2087-2132.

Köhnk S., Kleinteich T., Brandis D., Gorb S.N. 2017b. Biomechanics of pleon attachment in the European shore crab Carcinus maenas (Linnaeus, 1758) (Brachyura: Portunoidea: Carcinidae). J. Crustac. Biol. 37:142-150.

Kropp R.K. 1981. Additional Porcelain Crab Feeding Methods (Decapoda, Porcellanidae). Crustaceana. 40:307-310.

Lamichhaney S., Card D.C., Grayson P., Tonini J.F.R., Bravo G.A., Näpflin K., Termignoni-Garcia F., Torres C., Burbrink F., Clarke J.A., Sackton T.B., Edwards S.V. 2019. Integrating natural history collections and comparative genomics to study the genetic architecture of convergent evolution. Philos. Trans. R. Soc. B Biol. Sci. 374:20180248.

Losos J.B. 2011. Convergence, adaptation, and constraint. Evolution. 65:1827-1840.

Luque J. 2015. A puzzling frog crab (Crustacea: Decapoda: Brachyura) from the Early Cretaceous Santana Group of Brazil: frog first or crab first? J. Syst. Palaeontol. 13:153-166.

Luque J., Feldmann R.M., Schweitzer C.E., Jaramillo C., Cameron C.B. 2012. The oldest frog crabs (Decapoda: Brachyura: Raninoida) from the Aptian of northern South America. J. Crustac. Biol. 32:405-420.

Luque J., Schweitzer C.E., Santana W., Portell R.W., Vega F.J., Klompmaker A.A. 2017. Checklist of fossil decapod crustaceans from tropical America. Part I: Anomura and Brachyura. Nauplius. 25:1-85.

Luque J., Allison W.T., Bracken-Grissom H.D., Jenkins K.M., Palmer A.R., Porter M.L., Wolfe J.M. 2019a. Evolution of crab eye structures and the utility of ommatidia morphology in resolving phylogeny. BioRxiv. https://doi.org/10.1101/786087

Luque J., Feldmann R.M., Vernygora O., Schweitzer C.E., Cameron C.B., Kerr K.A., Vega F.J., Duque A., Strange M., Palmer A.R., Jaramillo C. 2019b. Exceptional preservation of mid-Cretaceous marine arthropods and the evolution of novel forms via heterochrony. Sci. Adv. 5:eaav3875.

Luque J., Cortés D., Rodriguez-Abaunza A., Cárdenas D., de Dios Parra J. 2020. Orithopsid crabs from the Lower Cretaceous Paja Formation in Boyacá (Colombia), and the earliest record of parasitic isopod traces in Raninoida. Cretac. Res. 116:104602.

Lv J., Li R., Su Z., Gao B., Ti X., Yan D., Liu G.J., Wang C., Liu P., Li J. 2020. A chromosome-level genome of Portunus trituberculatus provides insights into its evolution, salinity adaptation, and sex determination. Authorea. https://doi.org/1010.22541/au.159646761.15797764 
Ma K.Y., Qin J., Lin C.-W., Chan T.-Y., Ng P.K.L., Chu K.H., Tsang L.M. 2019. Phylogenomic analyses of brachyuran crabs support early divergence of primary freshwater crabs. Mol. Phylogenet. Evol. 135:62-66.

Martin A., Serano J.M., Jarvis E., Bruce H.S., Wang J., Ray S., Barker C.A., O’Connell L.C., Patel N.H. 2016. CRISPR/Cas9 Mutagenesis Reveals Versatile Roles of Hox Genes in Crustacean Limb Specification and Evolution. Curr. Biol. 26:14-26.

Martin J.W., Olesen J., Høeg J., editors. 2014. Atlas of Crustacean Larvae. Baltimore: Johns Hopkins University Press.

McLaughlin P.A. 1983. A Review of the Phylogenetic Position of the Lomidae (Crustacea: Decapoda: Anomala). J. Crustac. Biol. 3:431-437.

McLaughlin P.A., Lemaitre R. 1997. Carcinization in the Anomura-fact or fiction? I. Evidence from adult morphology. Contrib. Zool. 67:79-124.

McLaughlin P.A., Lemaitre R., Tudge C.C. 2004. Carcinization in the Anomura-fact or fiction? II. Evidence from larval, megalopal and early juvenile morphology. Contrib. Zool. 73:165-206.

Michaud M., Veron G., Fabre A. 2020. Phenotypic integration in feliform carnivores: Covariation patterns and disparity in hypercarnivores versus generalists. Evolution.

Minagawa M. 1990. Complete larval development of the red frog crab Ranina ranina (Crustacea, Decapoda, Raninidae) reared in the laboratory. Nippon Suisan Gakkaishi. 56:577-589.

Mongiardino Koch N., Parry L.A. 2020. Death is on Our Side: Paleontological Data Drastically Modify Phylogenetic Hypotheses. Syst. Biol. 69:1052-1067.

Noever C., Glenner H. 2017. The origin of king crabs: hermit crab ancestry under the magnifying glass. Zool. J. Linn. Soc. 2:300-318.

Olson E.C., Miller R.L. 1958. Morphological Integration. Chicago: University of Chicago Press.

Palmer A.R. 1979. Fish predation and the evolution of gastropod shell sculpture: experimental and geographic evidence. Evolution. 33:697-713.

Poore A.G.B., Ahyong S.T., Lowry J.K., Sotka E.E. 2017. Plant feeding promotes diversification in the Crustacea. Proc. Natl. Acad. Sci.:201706399.

Prado L.A.C., Luque J., Franca Barreto A., Palmer A.R. 2018. New brachyuran crabs from the AptianAlbian Romualdo Formation, Santana Group of Brazil: evidence for a tethyan connection to the Araripe Basin. Acta Palaeontol. Pol. 63.

Reese E.S. 1968. Shell use: an adaptation for emigration from the sea by the coconut crab. Science. 161:385-386.

Rincon-Sandoval M., Duarte-Ribeiro E., Davis A.M., Santaquiteria A., Hughes L.C., Baldwin C.C., SotoTorres L., Acero P. A., Walker H.J., Carpenter K.E., Sheaves M., Ortí G., Arcila D., Betancur-R. R. 2020. Evolutionary determinism and convergence associated with water-column transitions in marine fishes. Proc. Natl. Acad. Sci.:202006511.

Robin N., Bakel B.W.M. van, Hyžný M., Cincotta A., Garcia G., Charbonnier S., Godefroit P., Valentin X. 2019. The oldest freshwater crabs: claws on dinosaur bones. Sci. Rep. 9:20220.

Robins C.M., Klompmaker A.A. 2019. Extreme diversity and parasitism of Late Jurassic squat lobsters (Decapoda: Galatheoidea) and the oldest records of porcellanids and galatheids. Zool. J. Linn. Soc. 187:1131-1154.

Schnabel K.E., Ahyong S.T., Maas E.W. 2011. Galatheoidea are not monophyletic - Molecular and morphological phylogeny of the squat lobsters (Decapoda: Anomura) with recognition of a new superfamily. Mol. Phylogenet. Evol. 58:157-168.

Scholtz G. 2014. Evolution of crabs-history and deconstruction of a prime example of convergence. Contrib. Zool. 83:87-105.

Scholtz G. 2020. Eocarcinus praecursor Withers, 1932 (Malacostraca, Decapoda, Meiura) is a stem group brachyuran. Arthropod Struct. Dev. 59:100991.

Scholtz G., Richter S. 1995. Phylogenetic systematics of the reptantian Decapoda (Crustacea, Malacostraca). Zool. J. Linn. Soc. 113:289-328. 
Scholtz G., Knötel D., Baum D. 2020. D’Arcy W. Thompson's Cartesian transformations: a critical evaluation. Zoomorphology. 139:293-308.

Schweitzer C.E., Feldmann R.M. 2010. The Decapoda (Crustacea) as Predators on Mollusca Through Geologic Time. Palaios. 25:167-182.

Schweitzer C.E., Feldmann R.M. 2015. Faunal turnover and niche stability in marine Decapoda in the Phanerozoic. J. Crustac. Biol. 35:633-649.

Seeley R.H. 1986. Intense natural selection caused a rapid morphological transition in a living marine snail. Proc. Natl. Acad. Sci. 83:6897-6901.

Serano J.M., Martin A., Liubicich D.M., Jarvis E., Bruce H.S., La K., Browne W.E., Grimwood J., Patel N.H. 2016. Comprehensive analysis of Hox gene expression in the amphipod crustacean Parhyale hawaiensis. Dev. Biol. 409:297-309.

Serb J.M., Sherratt E., Alejandrino A., Adams D.C. 2017. Phylogenetic convergence and multiple shell shape optima for gliding scallops (Bivalvia: Pectinidae). J. Evol. Biol. 30:1736-1747.

Sherratt E., Serb J.M., Adams D.C. 2017. Rates of morphological evolution, asymmetry and morphological integration of shell shape in scallops. BMC Evol. Biol. 17:248.

Shiga Y., Kato Y., Aragane-Nomura Y., Haraguchi T., Saridaki T., Watanabe H., Iguchi T., Yamagata H., Averof M. 2017. Repeated co-option of a conserved gene regulatory module underpins the evolution of the crustacean carapace, insect wings and other flat outgrowths. bioRxiv. https://doi.org/10.1101/160010

Smith S.D., Pennell M.W., Dunn C.W., Edwards S.V. 2020. Phylogenetics is the New Genetics (for Most of Biodiversity). Trends Ecol. Evol. 35:415-425.

Song L., Bian C., Luo Y., Wang L., You X., Li J., Qiu Y., Ma X., Zhu Z., Ma L., Wang Z., Lei Y., Qiang J., Li H., Yu J., Wong A., Xu J., Shi Q., Xu P. 2016. Draft genome of the Chinese mitten crab, Eriocheir sinensis. GigaScience. 5:s13742-016.

Spitzner F., Meth R., Krüger C., Nischik E., Eiler S., Sombke A., Torres G., Harzsch S. 2018. An atlas of larval organogenesis in the European shore crab Carcinus maenas L. (Decapoda, Brachyura, Portunidae). Front. Zool. 15:27.

Steffel B.V., Smith K.E., Dickinson G.H., Flannery J.A., Baran K.A., Rosen M.N., McClintock J.B., Aronson R.B. 2019. Characterization of the exoskeleton of the Antarctic king crab Paralomis birsteini. Invertebr. Biol. 138:e12246.

Swanson B.O., George M.N., Anderson S.P., Christy J.H. 2013. Evolutionary variation in the mechanics of fiddler crab claws. BMC Evol. Biol. 13:137.

Tan M.H., Gan H.M., Dally G., Horner S., Moreno P.A.R., Rahman S., Austin C.M. 2018a. More limbs on the tree: mitogenome characterisation and systematic position of 'living fossil' species Neoglyphea inopinata and Laurentaeglyphea neocaledonica (Decapoda : Glypheidea : Glypheidae). Invertebr. Syst. 32:448-456.

Tan M.H., Gan H.M., Lee Y.P., Linton S., Grandjean F., Bartholomei-Santos M.L., Miller A.D., Austin C.M. 2018b. ORDER within the chaos: Insights into phylogenetic relationships within the Anomura (Crustacea: Decapoda) from mitochondrial sequences and gene order rearrangements. Mol. Phylogenet. Evol. 127:320-331.

Tan M.H., Gan H.M., Lee Y.P., Bracken-Grissom H., Chan T.-Y., Miller A.D., Austin C.M. 2019. Comparative mitogenomics of the Decapoda reveals evolutionary heterogeneity in architecture and composition. Sci. Rep. 9:10756.

Tang B., Wang Z., Liu Q., Wang Z., Ren Y., Guo H., Qi T., Li Y., Zhang H., Jiang S., Ge B., Xuan F., Sun Y., She S., Yam Chan T., Sha Z., Jiang H., Li H., Jiang W., Qin Y., Wang K., Qiu Q., Wang W., Li X., Ng N.K., Zhang D., Li Y. 2020a. Chromosome-level genome assembly of Paralithodes platypus provides insights into evolution and adaptation of king crabs. Mol. Ecol. Resour. 
Tang B., Wang Z., Liu Q., Zhang H., Jiang S., Li X., Wang Z., Sun Y., Sha Z., Jiang H., Wu X., Ren Y., Li H., Xuan F., Ge B., Jiang W., She S., Sun H., Qiu Q., Wang W., Wang Q., Qiu G., Zhang D., Li Y. 2020b. High-Quality Genome Assembly of Eriocheir japonica sinensis Reveals Its Unique Genome Evolution. Front. Genet. 10:1340.

Tang B., Zhang D., Li H., Jiang S., Zhang H., Xuan F., Ge B., Wang Z., Liu Y., Sha Z., Cheng Y., Jiang W., Jiang H., Wang Z., Wang K., Li C., Sun Y., She S., Qiu Q., Wang W., Li X., Li Y., Liu Q., Ren Y. 2020c. Chromosome-level genome assembly reveals the unique genome evolution of the swimming crab (Portunus trituberculatus). GigaScience. 9:giz161.

Timm L., Bracken-Grissom H.D. 2015. The forest for the trees: evaluating molecular phylogenies with an emphasis on higher-level Decapoda. J. Crustac. Biol. 35:577-592.

Tsang L.M., Chan T.-Y., Ahyong S.T., Chu K.H. 2011. Hermit to King, or Hermit to All: Multiple Transitions to Crab-like Forms from Hermit Crab Ancestors. Syst. Biol. 60:616-629.

Tsang L.M., Schubart C.D., Ahyong S.T., Lai J.C.Y., Au E.Y.C., Chan T.-Y., Ng P.K.L., Chu K.H. 2014. Evolutionary History of True Crabs (Crustacea: Decapoda: Brachyura) and the Origin of Freshwater Crabs. Mol. Biol. Evol. 31:1173-1187.

Vehof J., van der Meij S.E.T., Türkay M., Becker C. 2016. Female reproductive morphology of coralinhabiting gall crabs (Crustacea: Decapoda: Brachyura: Cryptochiridae). Acta Zool. 97:117-126.

Ventura T., Palero F., Rotllant G., Fitzgibbon Q.P. 2018. Crustacean metamorphosis: an omics perspective. Hydrobiologia. 825:47-60.

Vermeij G.J. 1977. The Mesozoic Marine Revolution: Evidence from Snails, Predators and Grazers. Paleobiology. 3:245-258.

Vidal-Gadea A.G., Rinehart M.D., Belanger J.H. 2008. Skeletal adaptations for forwards and sideways walking in three species of decapod crustaceans. Arthropod Struct. Dev. 37:95-108.

Vogt G. 2013. Abbreviation of larval development and extension of brood care as key features of the evolution of freshwater Decapoda. Biol. Rev. 88:81-116.

Wang Z., Tang D., Guo H., Shen C., Wu L., Luo Y. 2020. Evolution of digestive enzyme genes associated with dietary diversity of crabs. Genetica. 148:87-99.

Watanabe A., Fabre A.-C., Felice R.N., Maisano J.A., Müller J., Herrel A., Goswami A. 2019. Ecomorphological diversification in squamates from conserved pattern of cranial integration. Proc. Natl. Acad. Sci. 116:14688-14697.

Wolfe J.M., Breinholt J.W., Crandall K.A., Lemmon A.R., Moriarty Lemmon E., Timm L.E., Siddall M.E., Bracken-Grissom H.D. 2019. A phylogenomic framework, evolutionary timeline, and genomic resources for comparative studies of decapod crustaceans. Proc. R. Soc. B Biol. Sci. 286:20190079.

Yusuf L., Heatley M.C., Palmer J.P.G., Barton H.J., Cooney C.R., Gossmann T.I. 2020. Noncoding regions underpin avian bill shape diversification at macroevolutionary scales. Genome Res. 30:553-565.

Zhang X., Yuan J., Sun Y., Li S., Gao Y., Yu Y., Liu C., Wang Q., Lv X., Zhang X., Ma K.Y., Wang X., Lin W., Wang L., Zhu X., Zhang C., Zhang J., Jin S., Yu K., Kong J., Xu P., Chen J., Zhang H., Sorgeloos P., Sagi A., Alcivar-Warren A., Liu Z., Wang L., Ruan J., Chu K.H., Liu B., Li F., Xiang J. 2019. Penaeid shrimp genome provides insights into benthic adaptation and frequent molting. Nat. Commun. 10:1-14. 